\title{
ANÁLISE MICROBIOLÓGICA DA ÁGUA DE UM AÇUDE LOCALIZADO NO MUNICÍPIO DE MORRINHOS - CE
}

Andréa Maria Neves ${ }^{1}$, Maria Gleiciane Soares Coutinho ${ }^{1}$, Anny Sampaio Silva ${ }^{2}$, Layanne Mesquita Albuquerque Lopes ${ }^{2}$, Raquel Oliveira dos Santos Fontenelle ${ }^{2}$.

${ }^{1}$ Centro de Ciência e Tecnologia, Universidade Estadual do Ceará- UECE, FortalezaCE, Brasil (andreamarianeves@gmail.com).

${ }^{2}$ Laboratório de Microbiologia, Centro de Ciências Agrárias e Biológicas, Universidade Estadual Vale do Acaraú.

Recebido em: 03/10/2016 - Aprovado em: 21/11/2016 - Publicado em: 05/12/2016 DOI: 10.18677/EnciBio_2016B_104

Nas últimas décadas a população passou a ter uma maior preocupação com o meio ambiente e, a sociedade vem impondo ao governo a busca de uma melhor qualidade de vida. $\mathrm{O}$ avanço tecnológico e a expansão populacional proporcionaram ao homem a exploração de forma cada vez mais intensa dos recursos naturais do planeta Terra em função de suas necessidades. O presente estudo teve como objetivo avaliar a qualidade microbiológica da água de um açude que é utilizado para o abastecimento e que pertence ao município de Morrinhos - CE. Foram coletadas amostras de água em 03 pontos distintos do açude, nos meses de setembro de 2015 a fevereiro de 2016, totalizando 18 amostras. As amostras foram submetidas á determinação do Número Mais Provável (NMP) de Coliformes Termotolerantes, Coliformes Totais e a quantificação de bactérias mesófilas aeróbias. O NMP de Coliformes Termotolerantes variou de $1,1 \times 10$ a $<1,6 \times 10^{3} \mathrm{CTT} / 100 \mathrm{~mL}$, sendo identificada a presença de Escherichia coli em todas as amostras estudadas, e para Coliformes Totais variou de $1,1 \times 10$ a $9,0 \times 10^{2} \mathrm{CT} / 100 \mathrm{~mL}$. A quantificação de bactérias aeróbias mesófilas variaram de $0 \quad \mathrm{UFC} / \mathrm{mL}$ a $9,9 \times 10^{4} \mathrm{UFC} / \mathrm{mL}$. Considerando-se os resultados obtidos, é possível afirmar que as amostras analisadas do açude foram consideradas impróprias para consumo humano de acordo com os padrões microbiológicos estabelecidos pela legislação brasileira. Portanto, é de suma importância a implantação de medidas preventivas e um eficiente sistema de saneamento básico.

PALAVRAS-CHAVE: Açude. Coliformes. Contaminação.

\section{ANALYSIS MICROBIOLOGICAL GIVES WATER IN ONE WEIR LOCATED AT THE COUNT IN MORRINHOS-CE}

\begin{abstract}
In recent decades the population has gained a greater concern for the environment and society is imposing on the government to search for a better quality of life. Technological advances and population growth gave the man the operation of an increasingly intense natural resources of planet Earth according to their needs. This study aimed to evaluate the microbiological quality of water from a dam that is used
\end{abstract}


to supply and which belongs to the municipality of Morrinhos - CE. Water samples were collected at 03 different points of the weir, from September 2015 to February 2016, totaling 18 samples. The samples were submitted will determine the Most Probable Number (MPN) of fecal coliforms, Total Coliforms and quantification of aerobic mesophilic bacteria. The thermotolerant coliforms MPN varied to $1.1 \times 10$ $<1,6 \times 103 \mathrm{CTT} / 100 \mathrm{~mL}$, identified the presence of Escherichia coli in all the samples studied and ranged from $1.1 \times 10$ Total Coliforms the CT 9,0x102 / 100mL. Quantification of mesophilic aerobic bacteria ranged from 0 CFU / $\mathrm{ml}$ to $9,9 \times 104$ $\mathrm{CFU} / \mathrm{mL}$. Considering the results, it is clear that the samples analyzed the dam were considered unfit for human consumption in accordance with the microbiological standards established by Brazilian law. Therefore, it is of paramount importance to implementation of preventive measures and an efficient sewerage system.

KEYWORDS: Weir. Coliforms. Contamination.

\section{INTRODUÇÃO}

A água é um bem natural de suma importância, uma vez que, a presença desse recurso no planeta é um fator decisivo para existência de vida, sendo também uma das principais substâncias consumida pelo homem, a qual está intrinsecamente ligada aos direitos fundamentais (NERES, 2010 ;MARQUES et al., 2015). Entretanto, embora abundantes, as fontes hídricas são mal distribuídas na superfície do planeta, inclusive no território brasileiro, pois em algumas regiões, onde se encontra a maior parte da população, os recursos hídricos disponíveis não são suficientes para o abastecimento (BETEMPS et al., 2014). Conforme CAMARGO \& PAULOSSO (2009) $97 \%$ da água disponível no globo é salgada, $2 \%$ formam as geleiras e icebergs e, apenas $1 \%$ da água doce está disponível para o consumo, para a utilização na agricultura, na indústria e no uso doméstico. Além disso, é frenquente o mau uso das águas pelo homem, acarretando desta forma a escassez relativa e também a degradação da qualidade, tornando-a inapropriada para consumo (EUBA NETO et al., 2012).

A região do nordeste brasileiro possui a maior cobertura de açudes construídos no país, os quais são utilizados para inúmeras finalidades: irrigação, abastecimento humano, dessedentação de animais, piscicultura, entre outros (LIMA \& MENDES, 2015). Embora importantes muitos dos açudes construídos estão frequentemente salinizados ou ainda contaminados por algas tóxicas, resíduos agrotóxicos, bem como, esgotos domésticos e industriais, tornando a água imprópria para o consumo do homem e também dos animais. Entretanto, muitas vezes, estes reservatórios constituem o único recurso de abastecimento disponível para a população (MOURA et al., 2011).

Desta forma, para que a água esteja própria para consumo do homem, faz-se necessário a realização do controle de qualidade, cuja finalidade é definir se a mesma está de acordo com parâmetros químicos, físicos, radioativos e microbiológicos (MARQUES et al., 2015). Habitualmente o monitoramento das condições sanitárias de água para consumo é realizado através das bactérias do grupo dos Coliformes Totais e Coliformes Termotolerantes, que quando presentes tornam a água imprópria para consumo. Estes grupos são considerados indicadores microbiológicos, pois são encontrados na microbiota intestinal do homem e de animais homeotérmicos (ZULPO et al., 2006; DANELUZ \& TESSARO, 2015).

Os micro-organismos do grupo dos Coliformes Totais pertencem a família Enterobactereacea e são classificados como bacilos Gram negativos, não formadores de esporos e fermentadores de lactose, com produção de gás, em 24 a 
48 horas a $35^{\circ} \mathrm{C}$. Os Coliformes Termotolerantes, ant eriormente denominados Coliformes Fecais, são bactérias Gram negativas, não esporuladas e fermentadoras de lactose com produção de gás, em 48 horas a $45^{\circ} \mathrm{C}$ (SALES et al., 2016). A finalidade da escolha desse grupo de micro-organismos como indicadores de contaminação da água deve-se a elementos como: fácil identificação por técnicas simples, possuem um tempo de vida maior na água do que as bactérias patógenas intestinais e são organismos menos exigentes em termos nutricionais, além de serem úteis para medir a ocorrência e grau de poluição fecal. Muito embora, a grande maioria dessas bactérias não sejam patogênicas estas podem representar risco à saúde, danificando a qualidade da água, ocasionando sabores e odores desagradáveis (FUNASA, 2006).

A portaria 2914/2011 do Ministério da Saúde assegura que para a gestão de água potável e de qualidade, esta deve ser submetida a um conjunto de procedimentos realizados por responsáveis, cuja finalidade é garantir que a água fornecida a população seja segura para consumo. Além do mais, a portaria do Ministério da Saúde preconiza que a água pronta para consumo deve obedecer a um padrão de potabilidade aceitável de maneira que não ofereça riscos ao consumidor (BRASIL, 2011).

$\mathrm{O}$ açude da presente pesquisa fica localizado em um distrito de Morrinhos $\mathrm{CE}$. O mesmo constitui a principal fonte de abastecimento de água da população e, consequentemente tem importância relevante na manutenção da qualidade de vida local. Entretanto, os moradores próximos ao açude não dispõem de um sistema de saneamento básico adequado, o que poderá contribuir para a contaminação do mesmo. A população em geral, utiliza a água do açude para preparar alimentos e também para beber, no entanto, antes mesmo de ser consumida essa água é submetida à estação de tratamento local, a fim de torná-la apropriada para consumo.

Diante do exposto, o presente estudo teve como objetivo avaliar a qualidade microbiológica da água de um açude que é utilizado para o abastecimento e que pertence ao município de Morrinhos - $\mathrm{CE}$, por meio da contagem de bactérias aeróbios mesófilos, pela determinação de Coliformes Totais e Coliformes Termotolerantes e, identificar através de testes bioquímicos os micro-organismos isolados.

\section{Área de estudo}

\section{MATERIAL E MÉTODOS}

O município de Morrinhos está localizado no norte do estado do Ceará, entre as coordenadas geográficas de $40^{\circ} 07^{\prime}$ a $30^{\prime \prime}$ longitude W e 3ำ13' a $46^{\prime \prime}$ latitude S. Apresenta uma área territorial de $415,6 \mathrm{~km}^{2}$, com uma população estimada de 21.561 habitantes. Morrinhos esta a $191 \mathrm{~km}$ da capital Fortaleza, e apresenta basicamente duas estações climáticas: a chuvosa, compreendida entre os meses de janeiro a maio, e a seca compreendida de julho a dezembro. O clima é tropical quente, com temperatura anual em torno de $26^{\circ}$ a $28^{\circ}$, com média de $27^{\circ} \mathrm{C}$ (IBGE, 2014). 


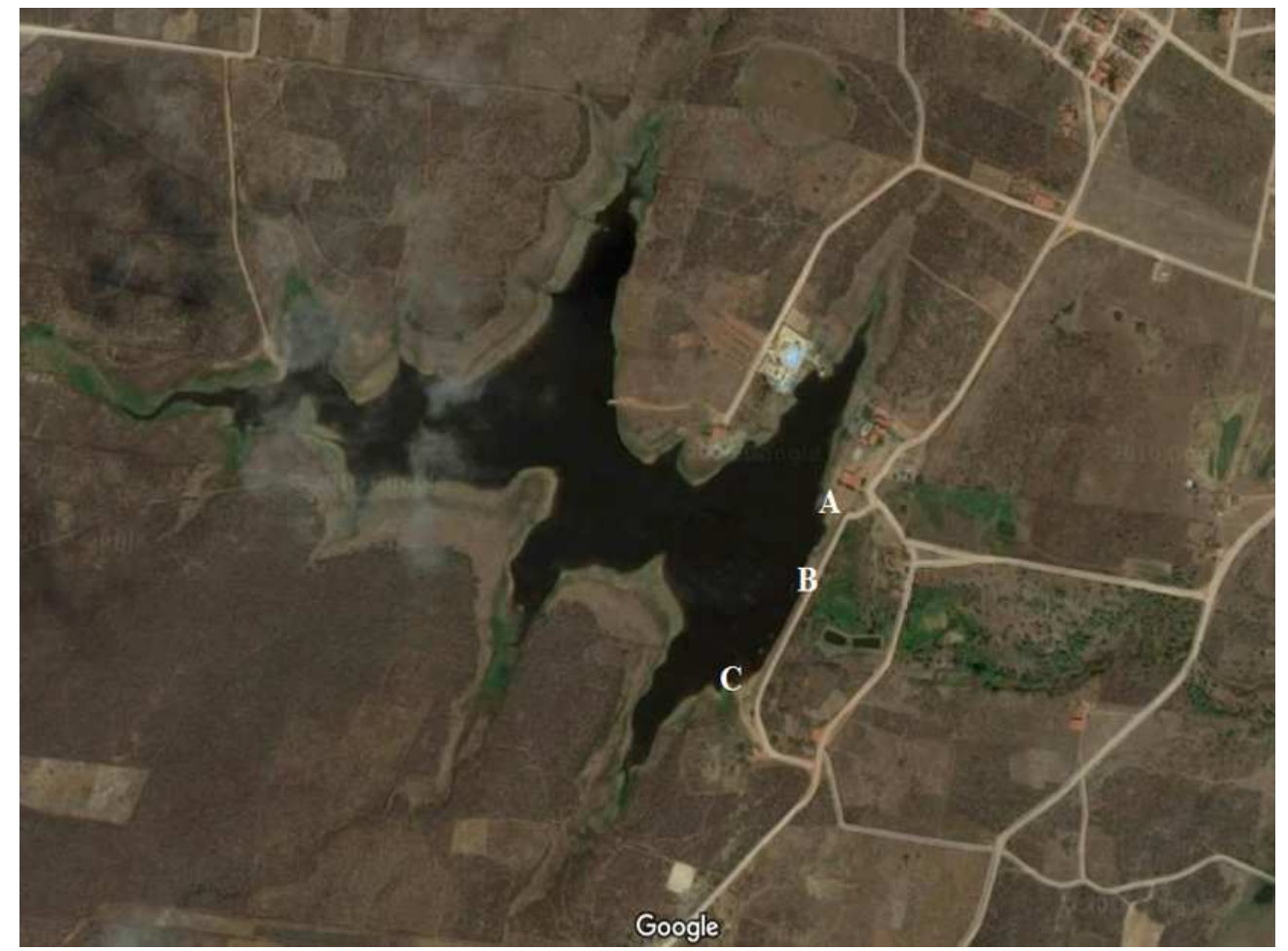

FIGURA 1: Imagem satélite mostrando o açude localizado no município de Morrinhos Ceará.

Fonte: Google maps

\section{Amostragem}

Para os testes microbiológicos foram coletadas 18 amostras de água em três pontos distintos do açude, nos meses de setembro de 2015 a fevereiro de 2016. $O$ ponto $\mathrm{A}$ e o ponto $\mathrm{B}$ localizam-se próximos a um parque aquático, e o ponto $\mathrm{C}$ fica próximo a uma vila de casas.

As amostras de água foram coletadas em frascos esterelizados, com capacidade de $1000 \mathrm{~mL}$. Após a coleta, os recipientes foram vedados, identificados e acondicionados em caixas isotérmicas, e posteriormente levados para serem analisados no Laboratório de Microbiologia da Universidade Estadual Vale do Acaraú-UVA, onde ocorreram as análises.

As amostras foram analisadas quanto à presença de Coliformes Totais e Coliformes Termotolerantes, utilizando-se a técnica dos tubos múltiplos, método quantitativo que permite determinar o Número Mais Provável-NMP (APHA, 2012). A contagem de micro-organismos mesófilos aeróbios foi realizada através da técnica do Pour plate: contagem de Unidades Formadoras de Colônia.

\section{Teste Presuntivo}

Para a prova presuntiva, foram preparados 15 tubos de Caldo Lactosado divididos em três séries de cinco, todos com tubos de Durham invertidos. Nos primeiros cinco tubos foram usados CL de concentração dupla, em que inoculou-se $10 \mathrm{~mL}$ da amostra em estudo em cada tubo (diluição 1:1). Nas demais séries foram utilizados CL de concentração simples, no qual foram inoculados $1 \mathrm{~mL}$ (diluição 1:10) da amostra na segunda série e $0,01 \mathrm{~mL}$ na última série (diluição 1:100). Posteriormente os tubos foram incubados em estufa a $3^{\circ} \mathrm{C}$ durante 48 horas. Após esse tempo, fez-se a leitura dos tubos, em que observou-se a formação de gás e turbidez como resultados positivos. 


\section{Teste Confirmativo}

Para o teste confirmativo, foram selecionados apenas os tubos positivos analisados na prova presuntiva. Dos tubos que apresentaram formação de gás na prova presuntiva foram retiradas alíquotas com o auxílio de uma alça e posteriormente inoculados em novos tubos contendo $5 \mathrm{~mL}$ de Caldo Bile Verde Brilhante (CBVB), todos com tubos de Durham invertidos. Os tubos foram incubados em estufa bacteriológica a $37^{\circ} \mathrm{C}$ por 48 horas para o crescimento de Coliformes Totais (CT).

Para a contagem de Coliformes Termotolerantes (CTT), foram retiradas alíquotas dos tubos positivos do teste presuntivo e transferidos para tubos contendo $5 \mathrm{~mL}$ de Caldo Escherichia coli (EC) e deixados em banho-maria a $45^{\circ} \mathrm{C}$ por 48 horas. A positividade destas análises foi observada através da produção de gás e turvação do meio nos tubos de Durham. Os resultados positivos foram anotados e posteriormente foi consultada a tabela de número mais provável (NMP).

\section{Quantificação e isolamento de Escherichia coli}

Dos tubos positivos do caldo EC para CTT foram retiradas alíquotas e estriadas em placas contendo Ágar Eosina Azul de Metileno (EMB) e que posteriormente foram incubadas a $3^{\circ} \mathrm{C}$ por 24 horas. Após o tempo de incubação foram selecionadas as colônias típicas para Escherichia coli com coloração verde brilhante das placas de EMB e logo em seguida semeada em tubos de ensaio contendo Tryptic Soy Agar (TSA) e incubados em estufa á $37^{\circ} \mathrm{C}$ por 24 horas. Após o tempo de incubação, as cepas isoladas de coliformes foram identificadas, segundo suas características através de testes bioquímicos $(\mathrm{ImViC}=$ Indol, Vermelho de Metila, Voges-Proskauer e Citrato de Simmons) segundo MEHLMAN et al. (1984).

\section{Contagem Padrão em Placas}

Para contagem de bactérias aeróbias mesófilas foi feita a técnica do "Pour Plate". De cada amostra de água foram realizadas três diluições $\left(10^{-1}, 10^{-2}\right.$ e $\left.10^{-3}\right)$, das quais foi retirado $1 \mathrm{~mL}$ de cada amostra e adicionada em placas de Petri esterilizadas. Posteriormente foram adicionados $15 \mathrm{~mL}$ de Plate Count Agar (PCA) para contagem, em que misturou-se o inóculo com o meio de cultura, logo depois homogeneizou-se através de movimentos suaves, numa superfície plana em movimentos em forma de oito e deixou-se a temperatura ambiente até a completa solidificação do Ágar. Após a total solidificação do meio de cultura nas placas, as mesmas foram incubadas de forma invertidas em estufa a $37^{\circ} \mathrm{C}$ por 24 horas. Após o tempo de incubação realizou-se a contagem das Unidades Formadoras de Colônia (UFC) com o auxílio de um contador de colônias. Das duplicatas que apresentaram número entre 1 e 250 UFC, multiplicou-se a média aritmética das placas em duplicatas pelo respectivo fator de diluição. Os resultados foram registrados em $\mathrm{UFC} / \mathrm{mL}$.

\section{RESULTADOS E DISCUSSÃO}

Os resultados obtidos da quantificação dos valores do Número Mais Provável (NMP) de Coliformes Termotolerantes (CTT), Coliformes Totais (CT), Escherichia coli e bactérias aeróbias mesófilas obtidos das 18 amostras coletadas em um açude localizado em um distrito de Morrinhos - CE estão apresentados na Tabela 1. 
TABELA 1. Número Mais Provável (NMP) de Coliformes Termotolerantes (CTT), Coliformes Totais (CT), pesquisa de Escherichia coli e contagem de micro-organismos aeróbios mesófilos nas águas do açude localizado no distrito de Morrinhos - CE.

\begin{tabular}{|c|c|c|c|c|}
\hline $\begin{array}{l}\text { AMOSTRAS/ } \\
\text { PONTOS }\end{array}$ & $\begin{array}{c}\text { NMP de } \\
\text { CTT }^{\star} / 100 \mathrm{~mL}\end{array}$ & $\begin{array}{c}\text { NMP de } \\
\mathrm{CT}^{\star \star} / 100 \mathrm{~mL}\end{array}$ & $\begin{array}{c}\text { Escherichia } \\
\text { coli }\end{array}$ & $\begin{array}{c}\text { Micro- } \\
\text { organismos } \\
\text { aeróbios } \\
\text { mesófilos } \\
\text { (UFC } / \mathrm{mL} \text { ) }\end{array}$ \\
\hline \multicolumn{5}{|l|}{ PONTO A } \\
\hline A 1 & $2,2 \times 10^{2}$ & $3,4 \times 10$ & + & $5,1 \times 10^{2}$ \\
\hline A 2 & $3,4 \times 10$ & $3,3 \times 10$ & - & $3,8 \times 10^{2}$ \\
\hline A 3 & $2,3 \times 10$ & $3,0 \times 10$ & - & $4,2 \times 10^{2}$ \\
\hline A 4 & $5,0 \times 10$ & $1,1 \times 10^{2}$ & - & $2,4 \times 10^{4}$ \\
\hline A 5 & $3,4 \times 10$ & $3,3 \times 10$ & - & $1,8 \times 10^{3}$ \\
\hline A 6 & $3,0 \times 10$ & $1,4 \times 10^{2}$ & + & $5,9 \times 10^{3}$ \\
\hline \multicolumn{5}{|l|}{ PONTO B } \\
\hline A 1 & $2,2 \times 10$ & $1,1 \times 10$ & + & $5,3 \times 10^{2}$ \\
\hline A 2 & $1,7 \times 10$ & $1,3 \times 10^{2}$ & + & $8,0 \times 10^{2}$ \\
\hline A 3 & $1,1 \times 10$ & $2,2 \times 10$ & - & $9,9 \times 10^{4}$ \\
\hline A 4 & $1,7 \times 10$ & $5,0 \times 10$ & + & $9,9 \times 10^{2}$ \\
\hline A 5 & $>1,6 \times 10^{3}$ & $3,5 \times 10^{2}$ & + & $7,6 \times 10^{2}$ \\
\hline A 6 & 7.0 & $3,5 \times 10^{2}$ & + & $8.6 \times 10^{2}$ \\
\hline \multicolumn{5}{|l|}{ PONTO C } \\
\hline A 1 & $2,2 \times 10^{2}$ & $9,0 \times 10^{2}$ & - & $6,5 \times 10$ \\
\hline A 2 & $3,4 \times 10$ & $5,0 \times 10^{2}$ & - & 0 \\
\hline A 3 & $3,4 \times 10$ & $3,4 \times 10$ & - & $3,0 \times 10^{4}$ \\
\hline A 4 & $8,0 \times 10$ & $3,3 \times 10$ & + & $5,5 \times 10^{3}$ \\
\hline A 5 & $>1,6 \times 10^{3}$ & $3,5 \times 10^{2}$ & - & $1,1 \times 10^{3}$ \\
\hline A 6 & $3,5 \times 10^{2}$ & $3,5 \times 10^{2}$ & + & INC \\
\hline
\end{tabular}

FONTE: Dados da pesquisa, 2016.

${ }^{*} \mathrm{CTT}$ : Coliformes Termotolerantes

${ }^{* *} \mathrm{CT}$ : Coliformes Totais

UFC: Unidades Formadoras de Colônias

O NMP de Coliformes Termotolerantes nas 18 amostras avaliadas variou de $1,1 \times 10$ a $>1,6 \times 10^{3} \mathrm{CTT} / 100 \mathrm{~mL}$. Os pontos $\mathrm{A}$, B e C apresentaram presença de Escherichia coli. Conforme a portaria $n^{\circ} 518 / 2011$ do Ministério da Saúde (MS) BRASIL, 2011, todas as amostras (100\%) de água analisadas, apresentaram-se impróprias para consumo humano, uma vez que, a legislação vigente que determina as regras de potabilidade das águas para consumo humano, proíbe a presença de Escherichia coli ou Coliformes Termotolerantes em amostras de $100 \mathrm{~mL}$ de água. ANDRADE et al. (2015) ao analisarem o perfil microbiológico de amostras de águas de um dos principais rios da região do semiárido paraibano, o Rio Piancó, observaram que estas foram consideradas impróprias para uso, indicando altos valores de Coliformes Termotolerantes sendo também identificada a presença de Escherichia coli em todas as amostras estudadas, estes resultados foram semelhantes aos encontrados na presente pesquisa.

MISAEL et al. (2015) ao analisarem amostras de águas do Açude do Boqueirão, poços particulares e do Açude de Várzea Grande, localizados nas ENCICLOPÉDIA BIOSFERA, Centro Científico Conhecer - Goiânia, v.13 n.24; p.1105 
cidades de Campina Grande, Cuité e Picuí, respectivamente, verificaram que, nenhuma das amostras analisadas apresentou Coliformes Termotolerantes, sugerindo que as mesmas estão aptas para consumo. Resultados semelhantes foram observados por MARQUES et al. (2015) que ao avaliarem a água do açude Engenheiro Ávidos, concluíram que o mesmo encontrava-se dentro do limite aceitável pelo Conselho Nacional do Meio Ambiente-CONAMA.

Os valores do Número Mais Provável de Coliformes Totais obtidos nas amostras coletadas dos três pontos distintos do açude apresentaram-se na faixa de $1,1 \times 10$ a $9,0 \times 10^{2} \mathrm{CT} / 100 \mathrm{~mL}$. Comparando os resultados obtidos com o índice NMP/100mL foram identificados Coliformes Totais em $100 \%$ das amostras. Apesar de que não exista um padrão determinado para o número de Coliformes Totais presentes em água in natura, a portaria 2.914 de 2011 do Ministério de Saúde (MS) BRASIL, 2011 indica que no controle da potabilidade da água, quando forem identificadas amostras com resultados positivos para Coliformes Totais, mesmo em ensaios presuntivos, deve-se adotar medidas de cunho preventivo de modo que, novas análises sejam realizadas em dias sucessivos até que se obtenha resultados plausíveis. MAGALHÃES et al. (2014) afirmam que, quando presentes em setores ambientais, os Coliformes Totais não constituem obrigatoriamente contaminação fecal, pois esse grupo abrange inúmeros gêneros e espécies de bactérias de origem não entérica.

Esses resultados estão condizentes com os estudos realizados por BATISTA \& FUCKS (2012), que ao efetuarem o monitoramento microbiológico em amostras de águas coletadas em diferentes pontos do rio Arroio Pessegueirinho, localizado no estado do Rio Grande do Sul, apresentaram uma alta taxa de contaminação por Coliformes Totais e Coliformes Termotolerantes, o que o torna impróprio para banho e consumo.

O número de bactérias mesófilas aeróbias nas 18 coletas variou de $0 \mathrm{UFC} / \mathrm{mL}$ a $9,9 \times 10^{4} \mathrm{UFC} / \mathrm{mL}$. Das 18 amostras avaliadas, $15(83,33 \%)$ estava acima dos valores máximos permitidos de bactérias aeróbias mesófilas determinadas pela legislação vigente, que define valores máximos de $500 \mathrm{UFC} / \mathrm{mL}$, (BRASIL, 2011). Resultados diferentes foram encontrados por SILVA et al. (2014) ao avaliarem os parâmetros microbiológicos da água de abastecimento em comunidades rurais pertencentes ao município de uma cidade localizada no sudoeste mineiro, verificaram que os valores de bactérias mesófilas aeróbias apresentaram valores abaixo de 500 UFC/mL, estando assim em conformidade com a legislação vigente.

Das 18 amostras analisadas foram isoladas 79 cepas, todas pertencentes à família Enterobacteriaceae. A família Enterobacteriaceae constitui uma das mais relevantes famílias bacterianas da qual fazem parte muitos patógenos que estão entre os principais causadores de infecção intestinal em vários países (COUTINHO et al., 2015). Dentre as 79 cepas isoladas do açude (100\%), 20 (25,3\%) correspondiam a Enterobacter agglomerans, $18(22,7 \%)$ a Escherichia coli, 16 $(20,2 \%)$ a Hafnia alvei, $11(13,9 \%)$ a Providencia alacalifaciens, $9(11,3 \%)$ a Serratia liquefaciens e $5(6,3 \%)$ a Proteus vulgaris (Gráfico 1). 


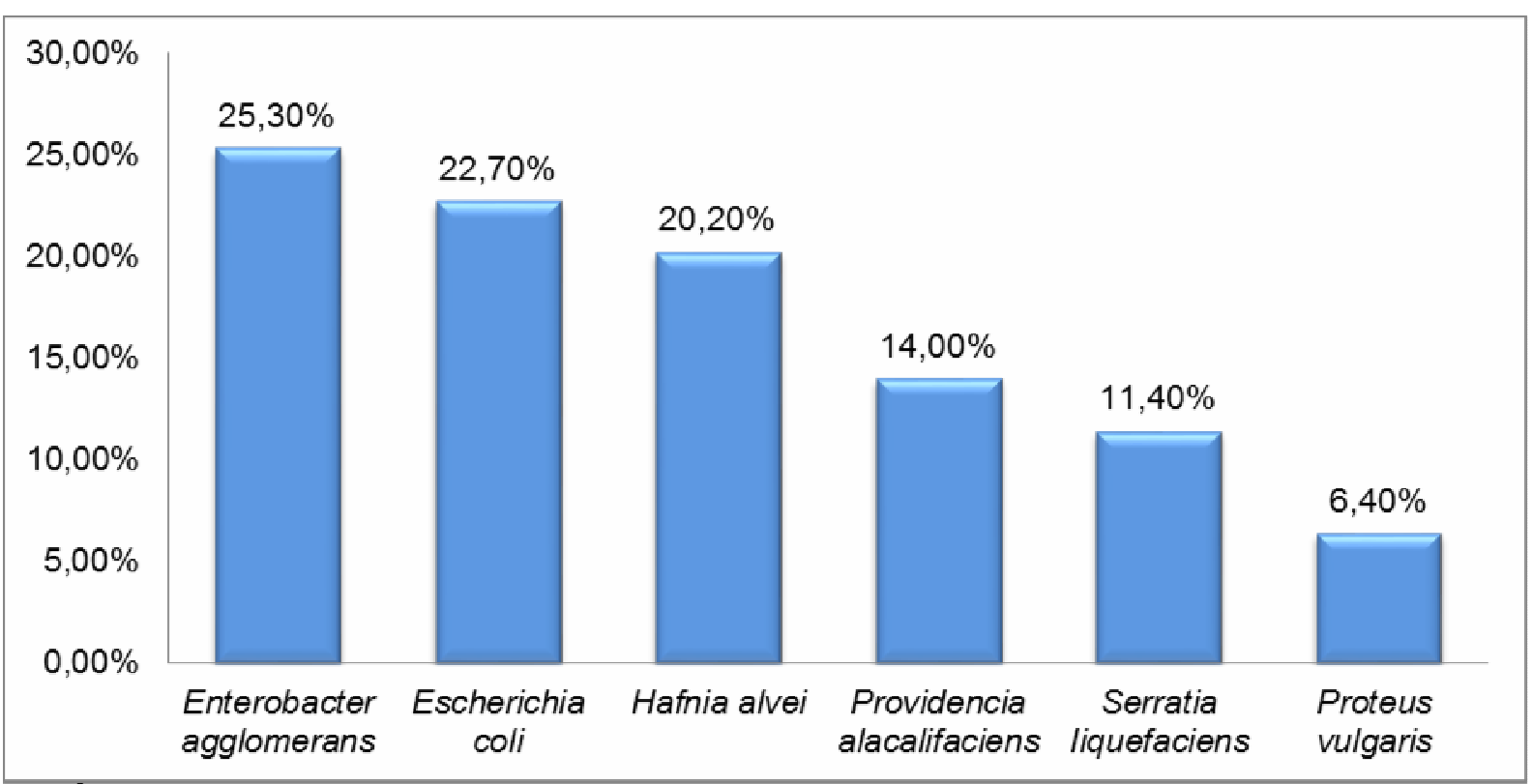

GRÁFICO 1. Distribuição das cepas da família Enterobacteriaceae identificadas nas amostras de águas do açude localizado no distrito de Morrinhos - CE.

FONTE: Dados da pesquisa, 2016.

A Escherichia coli é uma bactéria gram-negativa, não esporulada, aeróbia ou anaeróbia facultativa que se apresenta em forma de bacilos e que pertence a família Enterobactereacea. Estes micro-organismos, cujo habitat é a microbiota intestinal, tanto de seres humanos quanto de animais de sangue quente, quando encontrados na água ou alimentos indicam contaminação fecal. A Escherichia coli corresponde a um grupo de micro-organismos de interesse na saúde pública, pois algumas linhagens são patogênicas para o homem e animais, devido ao seu fator de virulência fatal (MAGALHÃES et al., 2014).

Entre os gêneros pertencentes à família Enterobactereacea também pode-se citar Enterobacter, Hafnia e Proteus. Estes micro-organismos são seres largamente distribuídos na natureza, e ocorrem naturalmente na microbiota intestinal do homem e de outros animais homeotérmicos. Entretanto, quando encontram condições ideais no hospedeiro, estes micro-organismos podem tornar-se patógenos oportunistas, sendo responsáveis por inúmeras infecções. Os gêneros Providencia e Serratia também são de cunho relevante, pois estas bactérias são patogênicas para o homem e são causadoras de algumas doenças de interesse médico (HOLT et al., 1994).

\section{CONCLUSÃO}

Considerando-se os resultados obtidos, é possível afirmar que as amostras analisadas do açude foram consideradas impróprias para consumo humano de acordo com os padrões microbiológicos estabelecidos pela legislação brasileira (Portaria n $518 / 2011$ ).

Os altos níveis de Coliformes Termotolerantes, Coliformes Totais, Escherichia coli e bactérias aeróbias mesófilas encontrados estão associados ao uso do açude para lavagem de veículos, banho e dessedentação de animais. Para isso, faz-se necessário a implantação de políticas públicas para a melhoria da qualidade da 
água, um eficiente sistema de saneamento básico, bem como, a sensibilização da população local quanto a importância da água e sua preservação.

\section{REFERÊNCIAS}

APHA-AMERICAN PUBLIC HEALTH ASSOCIATION. Standard methods for the examination of water and wastewater. $22 \mathrm{Ed}$. Washington DC, 2012.

ANDRADE, S. O. D.; CRISPIM, D. L.; SOUSA, M. A. D.; CHAVES, A. D. C. G.; MARACAJÁ, P. B. Análise espacial da qualidade microbiológica das águas do rio Piancó no trecho Coremas-Pombal-PB. Revista Verde de Agroecologia e Desenvolvimento Sustentável, v. 10, n.2, p. 157 - 161, 2015. Disponível em: <http://dx.doi.org/10.18378/rvads.v10i2.3551> doi: 10.18378/rvads.v10i2.3551

BATISTA, B. G.; FUCKS, M. B. Avaliação microbiológica da água do Arroio Pessegueirinho de Santa Rosa, noroeste do estado do Rio Grande do Sul. Monografias Ambientais, v. 9, n. 9, p. 2031-2037, 2012. Disponível em: <http://dx.doi.org/10.5902/223613085933>.doi: 10.5902/223613085933

BETEMPS, G. R.; SANCHES FILHO, P. J.; KERSTNER,T. Caracterização físicoquímica da água e determinação de metais pesados ( $\mathrm{Cr}, \mathrm{Cu}, \mathrm{Pb}$ e $\mathrm{Zn}$ ) no sedimento do riacho Arroio do Padre (Arroio do Padre, Brasil/RS). Revista Thema, v.11, n. 2, 2014. Disponível em: <http://dx.doi.org/10.15536/thema.11.2014.4-20.229> doi: 10.15536/thema.11.2014.4-20.229

BRASIL. Ministério da Saúde. Secretaria de Vigilância Sanitária. Portaria n: 2914 de Dezembro de 2011. Diário oficial da União, Brasília, 2011.

CAMARGO, F. M.; PAULOSSO, L.V. Avaliação qualitativa da contaminação microbiológica das águas de poços no município de Carlinda - MT. Semina: Ciências Biológicas e da Saúde, Londrina, v. 30, n. 1, p. 77-82, 2009. Disponível em:<http://dx.doi.org/10.5433/16790367.2009v30n1p77>.doi:10.5433/16790367.200 9v30n1p77

COUTINHO, M. G. S.; FERREIRA, C. D. S.; NEVES, A. M.; ALVES, F. R. L.; SOUZA, F. F. P. D.; FONTENELLE, R. O. D. S. Avaliação microbiológica e parasitológica de alfaces (Lactuta sativa L) comercializadas em feiras livres de Sobral-CE. Revista da Universidade Vale do Rio Verde, Três Corações, v. 13, n. 2, p. 388-397, 2015. Disponível em: <http://dx.doi.org/10.5892/ruvrd.v13i1.2320>. doi: 10.5892/ruvrd.v13i1.2320

DANELUZ; D., TESSARO, D.; Padrão físico-químico e microbiológico da água de nascentes e poços rasos de propriedades rurais da região sudoeste do Paraná. Arquivo do Instituto Biológico, v.82, 2015. Disponível em: <http://dx.doi.org/10.1590/1808-1657000072013>.doi:10.1590/1808-1657000072013

EUBA NETO, M.; SILVA, D. W. O.; RAMEIRO, F. C.; NASCIMENTO, D. E. S.; ALVES, A. D. S. Análises físicas, químicas e microbiológicas das águas do balneário Veneza na bacia hidrgráfica do médio Itapecuru, MA. Arquivos do Instituto Biológico, v.79, n.3 São Paulo, 2012. Disponível em: 
$<$ http://dx.doi.org/10.1590/S1808-16572012000300010>

doi:

$10.1590 / S 1808$

16572012000300010

FUNASA, Manual prático de análise de água. 2. ed. Brasília, DF: Assessoria de Comunicação e Educação em Saúde, 2006. 146 p.

GOOGLE MAPS. Disponível em: <https://www.google.com.br. Acesso em 10 de jul de 2016.

HOLT, J.G.; KRIEG, N.R.; SNEATH, P.H.A.; STALEY, J.T.; WILLIAMS, S.T. Facultatively anaerobic gram-negative roads. In: Bergey's Manual of determinative bacteriology. 9. ed., Baltimore: Williams \& Wilkins, 1994. 787p.

IBGE. Resultados do censo 2014. Disponível em: <http://www. ipece.ce.gov.br/publicacões/perfil_basico>Acesso: em:27 fev. 2014.

LIMA,J. R. D. C.; MENDES, R. A. S. Perfil abiótico e viabilidade à aquicultura no açude do Saco, sertão do Pajeú, Pernambuco. Revista Brasileira de Ciências Agrárias, v.10, n.1, p.153-158, 2015. Disponível em: <http://dx.doi.org/10.5039/agraria.v10i1a3616> doi:10.5039/agraria.v10i1a3616

MARQUES, A. E. F.; ALMEIDA, T. S. S. D.; ARAÚJO, A. D. S.; FILHO, E. A. D. S.; VIEIRA, A. C. B. Avaliação da qualidade microbiológica da água do açude Engenheiro Ávidos, Cajazeiras-PB. Revista Verde de Agroecologia e Desenvolvimento Sustentável, v. 10, n.5, p. 05-08, 2015. Disponível em: <http://dx.doi.org/10.18378/rvads.v10i5.3960> doi: 10.18378/rvads.v10i5.3960

MAGALHÃES, A.Y.; BATISTA, A. S. M.; FONTENELLE, R. O. D. S.; JULIÃO, M. S. D. S.; LOIOLOA, P. M. G.; MESQUITA, R. M.; AGUIAR, F. L. L. D.; OLIVEIRA, A. R. Qualidade microbiológica e físico-química da água dos açudes urbanos utilizados na dessedentação animal em Sobral, Ceará. Revista da Universidade Vale do Rio Verde, Três Corações, v. 12, n. 2, p. 141-148, 2014. Disponível em: <http://dx.doi.org/10.5892/ruvrd.v12i2.1417> doi: 10.5892/ruvrd.v12i2.1417

MEHLMAN, I. J.; ANDREWS, W.II.\& WENTZ, B. A. Coliform bacteria, p. 5.01-5.07, in Bacteriological Analytical Manual. Association of Official Analytical Chemists, 6th ed., Arlington, 1984.

MISAEL, C. G. A.; FERNANDES, C. V.; CHAVES, F. J. F.; SANTOS, J. S. B.; CAVALCANTE, J. N. A.; VASCONCELOS, S. F. D. Análise química e microbiológica da água em pontos de coleta distintos. Blucher Chemistry Proceedings, v. 3, n.1, 2015. Disponível em:<http://dx.doi.org/10.5151/chenpro-5erq-am15>doi: 10.5151/chenpro-5erq-am15

MOURA, E. M. D.; RIGHETTO, A. M.; LIMA, R. R. M. D. Avaliação da Disponibilidade Hídrica e da Demanda Hídrica no Trecho do Rio Piranhas-Açu entre os Açudes Coremas-Mãe D'água e Armando Ribeiro Gonçalves. Revista Brasileira de Recursos Hídricos, v.16, n.4, p. 07-19, 2011. Disponível em: < http://dx.doi.org/10.21168/rbrh.v16n4.p7-19> doi: 10.21168/rbrh.v16n4.p7-19

NERES, L. B. R. Avaliação físico-química básica da água consumida pela população urbana do município de Parnamirim/RN. HOLOS, v. 5, 2010. Disponível em: <http://dx.doi.org/10.15628/holos.2010.564> doi: 10.15628/holos.2010.564 
SILVA, J. R.; SÁ, O. R. D.; FRANÇA, N. Avaliação do tratamento simplificado de água para abastecimento em três comunidades de um município do sudoeste mineiro. Fórum Ambiental da Alta Paulista, v. 10, n. 12, p. 134-144, 2014. Disponível em: <http://dx.doi.org/10.17271/1980082710122014910>doi: $10.17271 / 1980082710122014910$

SALES, W. B.; KUCHAK, K. C.; CAVEIÃO, C. Determinação de coliformes totais e termotolerantes em hambúrgueres vendidos em fast foods na cidade de CuritibaParaná. Revista da Universidade Vale do Rio Verde, Três Corações, v. 14, n. 2, p. 412-420, 2016. Disponível em: <http://dx.doi.org/10.5892/ruvrd.v14i2.2698> doi: 10.5892/ruvrd.v14i2.2698

ZULPO, D. L.; PERETII, J.; ONO, L. M.; GARCIA, J. L. Avaliação microbiológica da água consumida nos bebedouros da Universidade Estadual do Centro-Oeste, Guarapuava, Paraná, Brasil. Semina: Ciências Agrárias, Londrina, v. 27, n. 1, p. 107-110, 2006. Disponível em: <http://dx.doi.org/10.5433/16790359.2006v27n1p107> doi: 10.5433/1679-0359.2006v27n1p107 